\title{
Uranium groundwater anomalies at LNGS: From the neutron flux background to the geodynamic processes
}

\author{
W. Plastino ${ }^{1,2}$, M. Laubenstein ${ }^{3}$, P. Aprili $^{3}$, M. Balata $^{3}$, \\ F. Bella ${ }^{1}$, A. Cardarelli ${ }^{3}$, B. Gallese ${ }^{3}$, L. Ioannucci ${ }^{3}$, \\ M. De VinCEnzi ${ }^{2}$, S. Nisi ${ }^{3}$, F. RugGieri ${ }^{2}$
}

${ }^{1}$ Department of Physics, University of Roma Tre - I-00146 Rome, Italy

${ }^{2}$ INFN, Section of Roma Tre - I-00146 Rome, Italy

${ }^{3}$ INFN, Gran Sasso National Laboratory - I-67100 Assergi, Italy

\begin{abstract}
Monitoring of chemical and physical groundwater parameters has been carried out worldwide in seismogenic areas with the aim to test possible correlations between their spatial and temporal variations and strain processes. It is shown in this paper that uranium groundwater anomalies, which were observed in cataclastic rocks crossing the underground Gran Sasso National Laboratory (LNGS), can be used as a possible strain meter in domains where continental lithosphere is subducted. Moreover, whereas at the Gran Sasso National Laboratory only the natural radioactivity in the rock, the concrete, as well as the induced part coming from interaction of cosmic ray muons with the rock or the detector materials itself were considered as possible sources for the neutron flux background, the water-rock interaction and its spatial-temporal variation induced by the hydrological pattern of the Gran Sasso aquifer must be taken into account. Water must be considered not only as moderator in concrete, but also as additional source for neutron flux modulation due to its variable concentration and its radioactivity.
\end{abstract}

This is an Open Access article distributed under the terms of the Creative Commons Attribution License 2.0, which permits unrestricted use, distribution, and reproduction in any medium, provided the original work is properly cited. 


\section{Introduction}

The neutron flux background plays a key-role in several research activities for Neutrino Physics and Dark Matter detection in underground environment. The neutron sources considered at deep underground are $(\alpha, \mathrm{n})$ reactions on light elements (e.g. Li, F, Na, etc.), spontaneous fission, mainly of ${ }^{238} \mathrm{U}$ [1], and those induced by cosmic ray muons. The Gran Sasso National Laboratory of the National Institute of Nuclear Physics (INFN) is located inside the largest aquifer of central Italy. The natural radioactivity in rock and materials used for the internal structures of the LNGS has been studied in detail $[2,3]$, and the specific activities of natural radionuclides are known with high accuracy for the characterization of neutron background at the LNGS [3]. Moreover, numerical simulations [1] and neutron flux measurements were carried out inside the LNGS [3-9]. Nevertheless, the contribution of the natural radioactivity in the ground water and its spatial-temporal variations induced by the water-rock interaction and the hydrological properties of the Gran Sasso aquifer have never been considered. The measurements of the neutron flux made during the years at the LNGS revealed differences of orders of magnitude [1], but it is difficult to correlate them with the aquifer properties at that time. Within the framework of the INFN scientific program ERMES (Environmental Radioactivity Monitoring for Earth Sciences) environmental radioactivity measurements were performed inside the LNGS: particularly, radon [10,11], radiocarbon [12], and tritium [13]. These measurements have shown the existence of different chemical-physical and fluid dynamical characteristics in the ground water. The measurements of the neutron flux [3-9] and the numerical simulations [1] have been performed in time intervals not exceeding the temporal and spatial variations of environmental radioactivity detected by ERMES [14-16]. Radon (Rn) as a possible candidate for earthquake precursor has been studied for a long time, but there is no clear evidence that it is really a precursor [19]. It has been suggested as one of several possible early signals, and its air or groundwater anomalies associated with earthquakes and air-rock or waterrock interactions were detected in several seismogenic areas worldwide. The physical processes associated with $\mathrm{Rn}$ anomalies are based on the changes of Rn emanation rates occurring due to strain signal near to the earthquake's nucleation point. Particularly, its behaviour before, during and after the main shock, considering the consolidated scheme for Rn release due to stressstrain processes in the rock is unclear. In the geological environment, the $\mathrm{Rn}$ concentration depends on the isotopic abundance of its parent radionuclides $\left({ }^{238} \mathrm{U}\right.$ (uranium) and ${ }^{226} \mathrm{Ra}$ (radium)), and on their geochemical patterns 
with reference to environmental redox and $\mathrm{pH}$ characteristics. The geodynamic processes induced by earthquakes can modify $\mathrm{Rn}$ migration patterns as a potential indicator of strain. However, the activity of $\mathrm{Rn}$ in fractured lithologies is difficult to predict, and the $\mathrm{Rn}$ concentration does not uniquely constrain the rock deformation or the chemical inhomogeneity nor its relationship with the transient crustal strain signals from aseismic fault slip, near to the earthquake's nucleation point [19].

\section{Experimental methods}

The measurements of the water samples taken during the monitoring of the LNGS ground water were performed using inductively coupled plasma mass specetrometry (ICP-MS) [17]. Each water sample taken at the monitoring sites inside the LNGS was analyzed for uranium (U), sodium (Na), magnesium $(\mathrm{Mg})$, potassium $(\mathrm{K})$, calcium $(\mathrm{Ca})$. Moreover, the electrical conductivity (EC), oxidation-reduction potential (ORP), and $\mathrm{pH}$ were determined with common laboratory equipment. As ICP-MS cannot be used to analyze the radioisotopes following uranium in the natural radioactive decay chain due to their extremely small concentration, some samples were filtered and analyzed by means of gamma-ray spectroscopy with high purity germanium (HPGe) detectors at the STELLA low background facility of the LNGS [18]. Using this technique the gamma active radionuclides in the uranium chain can be assessed, in particular the subchain of radium. Due to the different chemical behaviour of uranium and radium in water, it is important to know whether these two radionuclides are in secular equilibrium. The radium content in the water samples is determined via the direct daughter ${ }^{222} \mathrm{Rn}$ (radon) and its decay products. Special care has been taken in order to guarantee that no radon, a noble gas, can escape from the sample containers, and that radium and radon are in secular equilibrium.

\section{Results and discussion}

The uranium groundwater monitoring started on June 2008. The aim was to define the $\mathrm{Rn}$ groundwater transport processes through the cataclastic rocks [10], as well as to check its contribution to the neutron background at the LNGS [14]. The data of the U measurements carried out between June 2008 and May 2010 at four different sites (E1, E4 and E3, E3dx, see figure 1) show the presence of two different water groups. The existence of these groups is confirmed by the analyses of the stable isotopes of hydro- 
Table I: Concentrations of uranium $\left({ }^{238} \mathrm{U}\right)$ and radium $\left({ }^{226} \mathrm{Ra}\right)$, measured via inductively coupled plasma mass spectrometry (ICP-MS) and gamma-ray spectroscopy (HPGe) respectivley, as well as the ratio of the concentrations in several selected water samples. The concentrations are given in $10^{-9} \mathrm{gU} \mathrm{g}^{-1}$. The uncertainites are combined standard uncertainties.

\begin{tabular}{llccc}
\hline Location & Sampling date & ${ }^{238} \mathrm{U}$ (ICP-MS) & ${ }^{226} \mathrm{Ra}(\mathrm{HPGe})$ & ratio ${ }^{226} \mathrm{Ra} /{ }^{238} \mathrm{U}$ \\
\hline \hline E3dx & 18 Aug 2008 & $3.48 \pm 0.04$ & $1.5 \pm 0.2$ & $0.43 \pm 0.07$ \\
\hline E3dx & 09 Dec 2008 & $3.85 \pm 0.01$ & $2.3 \pm 0.3$ & $0.60 \pm 0.08$ \\
\hline E3dx & 10 Feb 2009 & $2.28 \pm 0.03$ & $1.1 \pm 0.2$ & $0.48 \pm 0.09$ \\
\hline E3dx & 28 Jun 2010 & $3.6 \pm 0.4$ & $1.1 \pm 0.2$ & $0.31 \pm 0.06$ \\
\hline
\end{tabular}

gen and oxygen $\left(\delta^{2} \mathrm{H}, \delta^{18} \mathrm{O}\right)$, and ${ }^{14} \mathrm{C}$ and ${ }^{3} \mathrm{H}$ analyses [15], as well. The peak structures in the uranium concentration (figure 2) were induced, according to our model, mainly by geodynamical processes through the fault and the hydrological pattern due to the high permeability of the cretaceous limestone forming of the Gran Sasso massif. Of course, the water-rock interaction and the ground water geochemistry modulate these variations. Due to the fact that thorium is generally almost insoluble in water, the thorium concentration gave only upper detection limits. Moreover, the structure of the aquifer is very complex due to geological and structural discontinuities that are induced by the distensive tectonic phase characterizing the Gran Sasso massif. Hydrostatic gradients as well as different hydrologic and geochemical properties in the various compartments of the aquifer are caused by semi-permeable and impermeable structures close to these discontinuities.

The $\mathrm{U}, \mathrm{Na}, \mathrm{Mg}, \mathrm{K}$ and $\mathrm{Ca}$ readings present a long-term variability, around the average value of about $20 \%$. In addition to this background. In the period A, from 23 June 2008 to 31 March 2009, the data show a distinct short-term peak structures of variations of 40 to $80 \%$. The values of EC, ORP and $\mathrm{pH}$ show relatively smooth fluctuations within $10 \%$. The situation is different for period B, going from 10 April 2009 to 31 May 2010. The larger peak-like structures for the $\mathrm{U}, \mathrm{Na}, \mathrm{Mg}, \mathrm{Ca}$ and $\mathrm{K}$ readings are no longer present. Only $\mathrm{K}$ and $\mathrm{Na}$ show few isolated peaks. The values of $\mathrm{EC}, \mathrm{ORP}$ and $\mathrm{pH}$ taken in period $\mathrm{B}$ show a quite similar behavior to that in period $\mathrm{A}$.

The water-rock interaction, modulated by percolation processes (due to meteoric events) above the water table of the Gran Sasso aquifer, do not justify the $\mathrm{U}$ anomalies [15]. Nevertheless there is a progressive increase of $\mathrm{U}$, and an enrichment in $\mathrm{Ca}, \mathrm{Mg}$, and $\mathrm{Na}$ observed in the groundwater located 


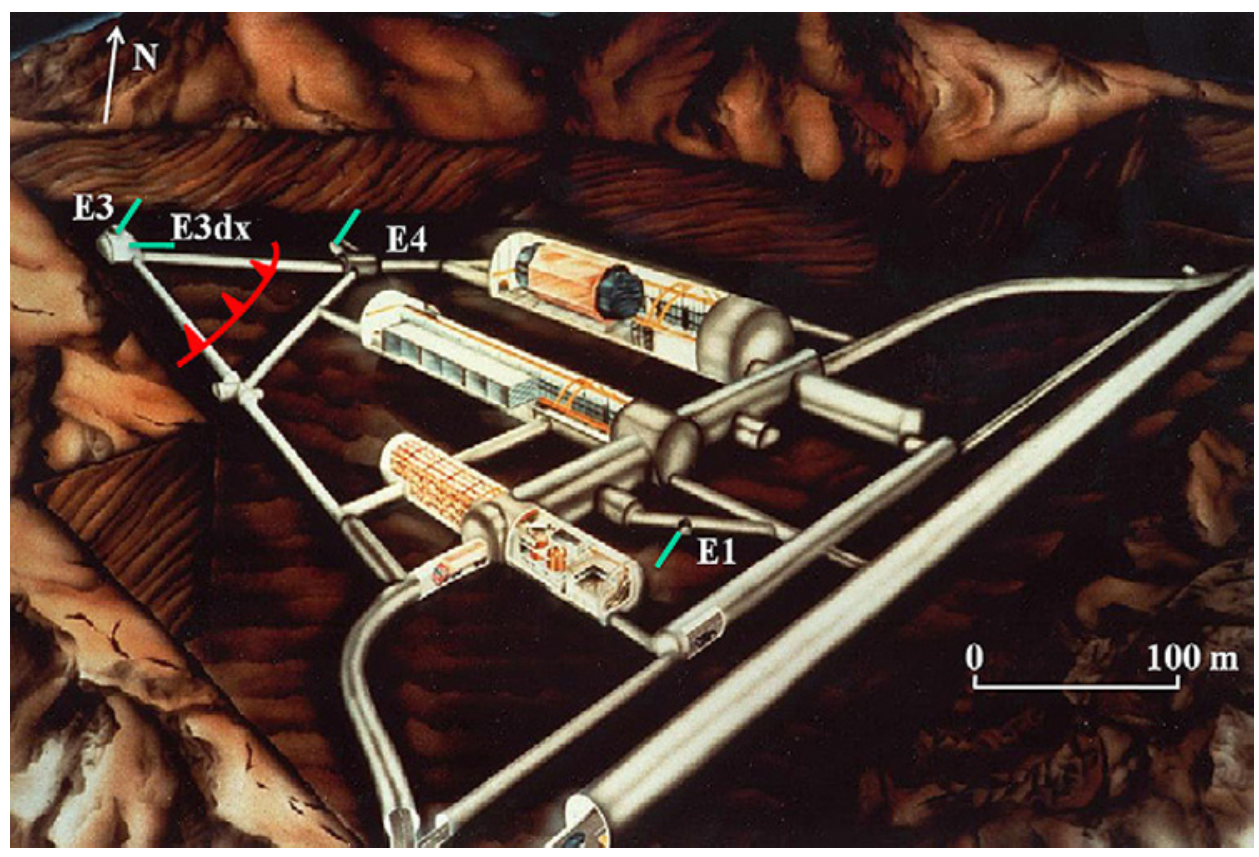

Figure 1: Schematic view of the LNGS-INFN. The overthrust fault (red line) and monitoring sites (E1, E3 and E4) are also shown. At site E3 there are two sampling points: E3 which is parallel to the overthrust fault in the North direction; and E3dx which is orthogonal to the fault in the E4 direction into the cataclastic rocks [16].

close to the main fault. This increase lasts for the whole preparatory phase of the L'Aquila earthquake of 6 April 2009. It can be explained as chemical interaction of the ground water with endogenic, upper mantle-derived carbon dioxide $\left(\mathrm{CO}_{2}\right)$ fluids. These fluids are produced by recycling and melting processes of carbonaceous sediments during the ongoing subduction of the continental Adriatic plate beneath the Italian peninsula [20].

In table I are reported the values of the uranium concentration (measured by ICP-MS) and of the radium concentration (measured with HPGe detectors) in some selected water samples, as well as the their ratio. It can clearly be seen that both values are not in secular equilibrium, and that radium is depleted with respect to uranium. A first interpretation is that in the rock-water interaction the conditions are such that the uranium is more soluble than the radium. As the concentration of the radium in the water is very low, the measurements are rather time consuming. The selected water samples up to now were those that showed also the highest uranium 
concentrations. New measurements of water samples with less uranium are underway in order to complete the picture.

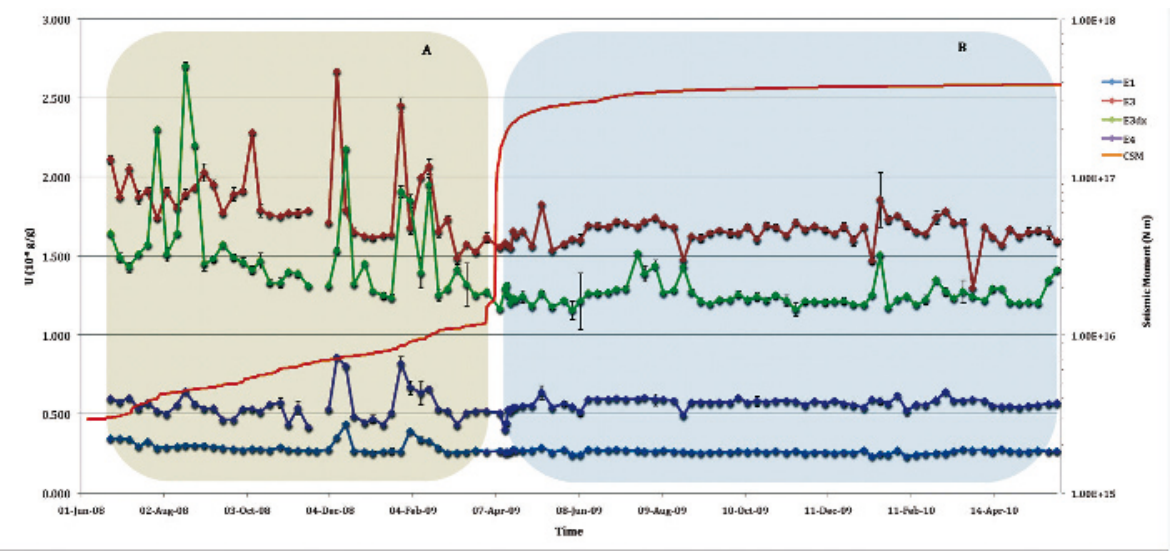

Figure 2: Time variation of $\mathrm{U}$ concentration in groundwater sampled at E1, E3, E3dx, and E4 from June 2008 to May 2010 [16].

\section{Conclusion}

The U groundwater anomalies observed before the earthquake, which occurred on 6 April 2009 in L'Aquila provide a key geochemical signal of a progressive increase of deep $\mathrm{CO}_{2}$ fluxes at middle-lower crustal levels. The repeated short-term enrichments of uranium in groundwater, which can be directly associated with the geodynamics of the earthquake, are a much more precise strain-meter than radon, whose presence is modulated by the radium content. The radium content is only about 30 to $60 \%$ of the uranium content. Furthermore the radon content is released by microfracturing only in a later moment, during the main shock and aftershocks. The neutron flux background at the LNGS is up to now only characterized by: (a) the radioactivity in the rock and the concrete, and (b) the induced radioactivity from cosmic ray muons interaction with rock or detectors themselves. Water was considered only as neutron moderator in the concrete. Nevertheless, the radioactivity concentration in the ground water has spatial-temporal variations showing that the neutron background is not steady-state, but can maybe vary by a few percent; for a better characterization of the neutron flux background this new piece of information should be considered.

The authors want to thank Dr. Lucia Votano, Director of the Gran Sasso 
National Laboratory, for her kind support and collaboration.

\section{References}

[1] Wulandari H. et al., Astropart. Phys., 22 (2004) 313.

[2] Esposito A., Pelliccioni M., Nucl. Sci. J., 22 (1985) 291.

[3] Bellotti E., Nucl. Instr. Meth., 246( 1988) 1.

[4] Rindi A. et al., Nucl. Instr. Meth. A, 272 (1988) 871.

[5] Aleksan R. et al., Nucl. Instr. Meth. A, 274 (1989) 203.

[6] Belli P. et al., Nuovo Cimento A, 101 (1989) 959.

[7] Cribier M. et al., Astropart. Phys., 4 (1995) 23.

[8] Arneodo F. et al., Nuovo Cimento A, 112 (1999) 819.

[9] Menghetti H. et al., Nuovo Cimento C, 29 (2006) 345.

[10] Plastino W., Bella F., Geophys. Res. Lett., 28 (2001) 2675.

[11] Plastino W., In Radionuclides in the Environment, edited by P. P. Povinec, J. A. Sanchez- Cabeza (Elsevier, Oxford, UK) 2006, pp. 335-342.

[12] Plastino W. et al., Radiocarbon, 43 (2001) 157.

[13] Plastino W. et al., Radiat. Meas., 43 (2007) 68.

[14] Plastino W. et al., J. Radioanal. Nucl. Chem., 813 (2009) 809.

[15] Plastino W. et al., J. Environ. Radioactiv., 101 (2010) 45.

[16] Plastino W. et al., J. Radioanal. Nucl. Chem., 288 (2011) 101.

[17] Nisi S. et al., Appl. Radiat. Isot., 67 (2009) 828.

[18] Arpesella C., Appl. Radiat. Isot., 47 (1996) 991.

[19] Roeloffs E., Nature, 399 (1999) 104.

[20] Peccerillo A., A Plio-Quaternary volcanism in Italy. Petrology, geochemistry, geodynamics (Springer, Heidelberg) 2005, pp. 1-365. 